\title{
Crowd-sourced data for geospatial sanitation planning in informal settlements
}

\author{
Tomas Holderness* \\ SMART Infrastructure Facility, \\ University of Wollongong, Australia \\ Email: tomas@uow.edu.au \\ *Corresponding author
}

\section{Ruth Kennedy-Walker and David Alderson}

School of Civil Engineering and Geosciences, Newcastle University, UK

Email: ruth.kennedywalker@gmail.com

Email: davidalderson07@gmail.com

\section{Barbara Evans}

School of Civil Engineering, University of Leeds, UK

Email: b.e.evans@leeds.ac.uk

\begin{abstract}
Crowd-sourced geospatial data from OpenStreetMap and the Map Kibera project were used to model and optimise a proposed road-based sanitation network for the settlement of Kibera in Nairobi, Kenya. A Boolean multicriteria suitability analysis was employed to identify areas of land for transfer station infrastructure construction. Selected locations were then used in a spatio-topological network model for a theoretical road-based faecal sludge management scheme to service 158 public toilets in Kibera using Vacutug technology. The network model was employed to further optimise the location of transfer stations based on minimising total sewage transport time across the network. In this manner the paper establishes the utility of maps generated by communities and citizens as providing vital on-the ground information for sanitation engineering planning. Such information is in lieu of traditional formal sources of geospatial data, which are often not available in informal settlements. The study demonstrates crowd-sourced maps, when combined with geographical information systems for analysis, present new opportunities for sanitation infrastructure provision planning in unplanned communities.
\end{abstract}

Keywords: sanitation; geographical information system; GIS; network analysis.

Reference to this paper should be made as follows: Holderness, T., Kennedy-Walker, R., Alderson, D. and Evans, B. (2016) 'Crowd-sourced data for geospatial sanitation planning in informal settlements', Int. J. Complexity in Applied Science and Technology, Vol. 1, No. 1, pp.22-34. 
Biographical notes: Tomas Holderness is a Chartered Geographer and Geomatics Research Fellow at the SMART Infrastructure Facility, University of Wollongong, Australia. He leads SMART's Open Source Geospatial Laboratory (OSGeo Lab), where his research applies geospatial analysis, Earth observation, and network modelling techniques to understanding urban infrastructure risk and resilience. Specifically, his research focuses on developing new architectures for the collection, integration, and analysis of geospatial media which have become ubiquitous in the urban environment to generate new modes of inquiry into the resilience of megacities to climate change.

Ruth Kennedy-Walker is an Environmental Engineer working in the Environment and Natural Resources Management Global Practice at the World Bank, focusing on the West African region. She has a Master's in Civil Engineering and recently graduated from Newcastle University, UK with a $\mathrm{PhD}$ in Environmental Engineering. Her research focused on identifying critical social and technical factors required to achieve sustainable Fecal Sludge Management services (road-based) in complex low-income informal settlements in Lusaka, The Republic of Zambia. During her PhD she completed an internship with the Water and Sanitation Program based in Jakarta, Indonesia and recently worked as a Research Assistant at Leeds University, $\mathrm{UK}$. Prior to her PhD she gained experience working in a UK water and wastewater utility as a Site Engineer and Design Coordinator.

David Alderson is a former Research Assistant, 2005 to 2015, in Geoinformatics at the School of Civil Engineering and Geosciences, Newcastle University, UK. He had been involved in a number of projects including the UKCP09 UK Climate Impact Programme product and Newcastle's Carbon Routemap. He worked from 2011 to 2015 as part of the Engineering and Physical Sciences Research Council, Infrastructure Transition Research Consortium (ITRC), looking at designing and developing tools for assessing challenges facing national infrastructure provision and maintenance in the UK, under different economic and demographic scenarios.

Barbara Evans holds the chair in Public Health Engineering in the School of Civil Engineering at the University of Leeds, UK. Her research activities centre on sanitation, hygiene and water services in the global south. Her research includes sanitation in low income urban communities, rural sanitation and water/sanitation in cities and towns. Within these areas, particular emphasis is placed on the development of effective strategies for management and disposal of faecal sludge, alternatives to conventional water borne sewerage in dense urban areas, effectiveness of rural sanitation programmes, sustainability and equity in community-wide approaches which eliminate open defecation, health impacts of open defecation practices, technologies and institutions to link community sanitation and water investments with city networks. Previously, she worked in industry and at the World Bank for 14 years before becoming an independent Consultant Civil Engineer in 2001. She joined the University in 2009 .

This paper is a revised and expanded version of a paper entitled 'An evaluation of spatial network modelling to aid sanitation planning in informal settlements using crowd-sourced data' presented at the First International Symposium for Next Generation Infrastructure, University of Wollongong, 4 October 2013. 


\section{Introduction}

In developing nations a lack of sanitation infrastructure results in significant risks to public health through the unsafe collection and treatment of sewage (United Nations, 2005; World Health Organisation, 2012). Exposure and vulnerability to such risks are exacerbated in rapidly urbanising and informal settlements, which have limited access to formal water and sanitation services (Isunju et al., 2011). It is estimated that only half of Africa's large cities have formal sewerage networks (Banerjee and Morella, 2011), and where infrastructure is not available, collection and transportation of waste is conducted via the road network (Tilley et al., 2008). Furthermore, restricted road and footpath networks in informal settlements mean that motorised collection and emptying vehicles are unable to access homes and shared toilet facilities. As a result waste collection and transportation processes are often undertaken manually, increasing exposure and health risks to communities (Tilley et al., 2008).

One solution is the 'Vacutug' developed by the United Nations Habitat program. The Vacutug is a small motorised vacuum pump truck designed to meet challenges of limited access to waste collection points in informal settlements (O'Riordan, 2009). Using Vacutugs as part of road-based fecal sludge management schemes has been widely cited as a potential method of reducing the aforementioned risks of informal sewage collection practices in developing nations (Tilley et al., 2008; O'Riordan, 2009). The viability of such a system has been proven through a number of successful field trials (O'Riordan, 2009; Chowdhry and Kone, 2012). However, it has also been highlighted that the success and scalability of sanitation solutions using Vacutugs are significantly limited by operational costs, maintenance requirements, limited carrying capacity $\left(0.5 \mathrm{~m}^{3}\right)$, and speed (5 km/h) (Tilley et al., 2008; O’Riordan, 2009).

A possible solution to decreasing costs is to reduce Vacutug transportation time by employing an intermediate transfer station for waste, located at the boundary of a settlement (Tilley et al., 2008). In this scenario Vacutugs only travel between collection point (e.g. toilet) and the transfer station where they deposit sewage in a holding tank. The holding tank is then periodically emptied by a large tanker truck that transports the waste across the main road network the remaining distance to the treatment plant (Tilley et al., 2008; O’Riordan, 2009).

When planning for road-based sanitation provision spatial network analysis can be used to optimise the location of transfer stations to reduce sewage transportation time and minimise associated costs. Network analysis within a geographical information system (GIS) enables the representation and modelling of road-based topological networks in a spatial manner for optimisation based on distance and travel time (Gastner and Newman, 2006). Such techniques have only recently become applicable in developing nations due to the emergence of crowd-sourced maps from informal settlements, which provide a source of data to generate network models (Zook et al., 2010; Paar and Rekittke, 2011). Prior to crowd-sourcing methodologies geospatial data from informal settlements was limited or non-existent, often because of the settlements' 'illegal' status (Hagen, 2010).

Crowd-sourced maps such as the OpenStreetMap project are created by community volunteers using GPS data, aerial photographs and existing paper maps (Haklay and Weber, 2008). Data are generated and organised using open source GISs and the underlying geospatial data is often released under an open license (Haklay and Weber, 
2008). As such, crowd-sourced maps have proved invaluable in areas where formal spatial data sources such as topographic surveys are limited. Crowd-sourced maps have been successfully used for community engagement (Hagen, 2010), urban planning (Paar and Rekittke, 2011), and disaster response (Zook et al., 2010). Crucially, the information provided by these maps is playing an increasingly important role in the lives and livelihoods of many inhabitants of developing cities worldwide (Berdou, 2011; Holderness, 2014). In these regions crowd-sourced spatial data sources have been cited as being more current, complete, and as reliable as the existing traditional formal sources of data (Hagen, 2010; Zook et al., 2010). The Map Kibera project is an example of one such scheme where members of a developing urban community working within the OpenStreetMap framework created for the first time a free and open highly detailed map of the informal settlement of Kibera in Nairobi, Kenya. The data collected includes land cover, the road/footpath network, and the location of amenities such as water taps, toilets, and health clinics (Hagen, 2010; Berdou, 2011; Paar and Rekittke, 2011).

This paper investigates the viability of using crowd-sourced geospatial data within a GIS to develop models of road-based sanitation networks to support sanitation planning in the informal settlement of Kibera, Nairobi. To this end, data from OpenStreetMap and the Map Kibera project were used to perform a two-step geospatial analysis; first, a Boolean multi-criteria suitability analysis of land cover was conducted to identify potential transfer station locations. Second, identified transfer station locations were integrated into a proposed road-based sewage treatment-transportation model designed to use Vacutug technology to service Kibera's communal toilets (Tilley et al., 2008; O'Riordan, 2009). Spatio-topological network analysis was then used optimise this network by identifying the optimum location of the transfer station which minimised total sewage transportation time.

\section{Materials and methods}

\subsection{Study area and data}

The informal settlement of Kibera is located approximately $5 \mathrm{~km}$ to the south west of Nairobi, Kenya. Kibera has an estimated population of 200,000 residents, and is situated on a 223 hectare site (Hagen, 2010). Figure 1 shows the location of Kibera in relation to the city of Nairobi. The settlement contains limited formal sanitation provision, with little or no formal sewerage network (Binale, 2011). Geospatial water and sanitation data were downloaded from the Map Kibera project and contained the locations of 158 public toilets that were used as collection nodes in the proposed road-based sanitation network. The Dandora treatment plant $20 \mathrm{~km}$ east of Nairobi (see Figure 1) was selected as a potential end-point for sewage from Kibera's toilets and located using OpenStreetMap data downloaded from 'Metro Extracts' website (Migurski, 2013). Dandora is a lagoon-based plant with a daily treatment capacity of $80,000 \mathrm{~m}^{3}$ that is discharged as partially treated effluent to the Nairobi river system (Engineering and Consulting Firms Association, 2008). 
Figure 1 Map showing Nairobi road network, Kibera settlement, and Dandora treatment works (see online version for colours)

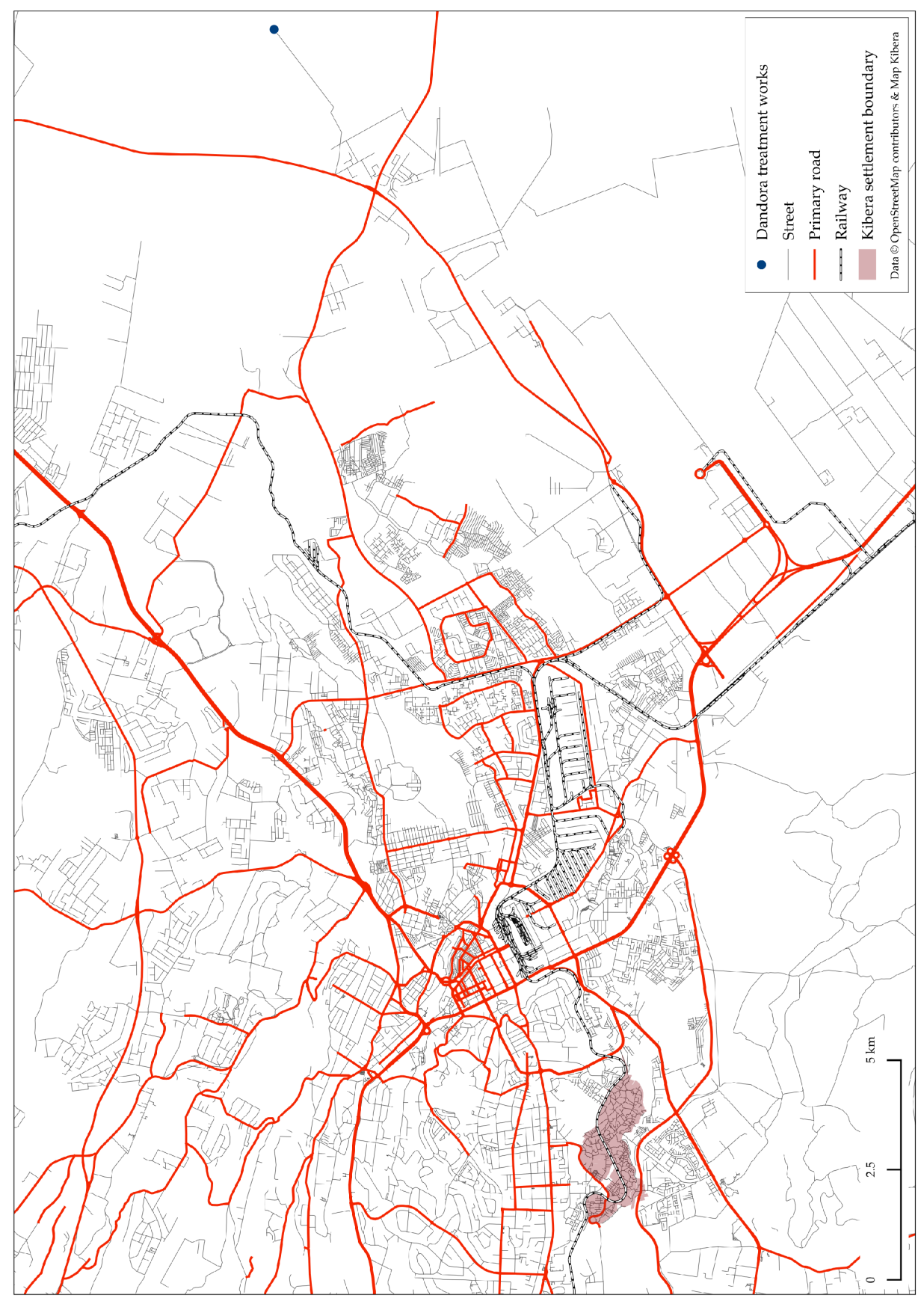


In addition to the location of public toilets, geospatial vector data of the Kibera settlement boundary and internal footpath network were downloaded from the Map Kibera project. City-scale data for the road network and land cover in Nairobi, derived from OpenStreetMap, were also downloaded from the Metro Extracts website. To manage the required data layers a spatial database was constructed, forming the foundation of the GIS used for analysis. The spatial database was created using the PostGIS extension to the open source PostgreSQL relational database management system, and contained tables representing each of the aforementioned input data layers. The open source 'QGIS' desktop GIS package was subsequently used to support analysis by visualising and interrogating layers within the database.

\subsection{Boolean multi-criteria suitability analysis of transfer stations}

A Boolean multi-criteria suitability analysis was used to identify potential locations for transfer stations based on spatial parameters required for transfer station infrastructure as reported in the literature (Tilley et al., 2008; O'Riordan, 2009; Binale, 2011). Boolean multi-criteria suitability analysis provides an indication of locational suitability based on a series of geospatial vector operations that test whether a location meets the specified criteria in a true/false manner (Malczewski, 2006).

The analysis was conducted in four stages with each stage representing one spatial characteristic required for an area of land to be classified as suitable, based on the spatial and topological relationships between the different layers of data (see Figure 2). Each level of analysis was performed using the information from OpenStreetMap and Map Kibera in the spatial database tables described above, principally the Kibera boundary, land cover in Nairobi, and the road network in Nairobi. Calculations were performed using spatial SQL, part of the PostGIS toolkit, to create a series of new tables representing locations identified as suitable for transfer station infrastructure.

Suitable land areas were selected if they met the following four conditions:

1 were within $5 \mathrm{~m}$ of a road connected to both Kibera and Nairobi

2 were within $50 \mathrm{~m}$ of the settlement boundary

3 were free from existing infrastructure development

4 had a total area of $64 \mathrm{~m}^{2}$ or greater.

Figure 2 shows the spatial analysis processes used to determine whether these conditions were met. The four processes are described in detail below using set theory notation to represent topological operations. Note that in this notation each data layer is represented as a unique set containing one or more individual polygon features, and for simplicity the individual point topology of polygon vertexes is not considered (Egenhofer and Franzosa, 1991; Worboys and Duckham, 2004).

First, a Euclidean buffer is applied to the Nairobi road network $A$ and the settlement boundary $B$ at 5 and $50 \mathrm{~m}$ respectively (see Figure 2). The output of this pre-processing step is two new polygon representations of these areas $A_{1}, B_{1}$. Areas of layer $A_{1}$ that fall outside $B_{1}$ form a new layer $C$ representing roads outside of Kibera.

$$
C:=A_{1} \backslash B_{1} \neq \varnothing
$$


Similarly, areas of the settlement boundary buffer $B_{1}$ outside existing infrastructure development $(I)$ form new layer $D$.

$$
D:=B_{1} \backslash I \neq \varnothing
$$

Thus, the intersection of $C$ and $D$ gives locations within specified distance for the road network, the settlement boundary, and free from existing infrastructure, satisfying conditions one, two and three.

$$
L:=C \cap D \neq \varnothing
$$

Lastly, polygons within $L$ with land area of $64 \mathrm{~m}^{2}$ or greater are identified as suitable locations for transfer stations (see Figure 2), satisfying the fourth and final condition.

$$
T:=\left\{x \in L: \operatorname{area}(x) \geq 64 \mathrm{~m}^{2}\right\}
$$

The centroids of these areas $(T)$ were subsequently used to represent transfer station nodes within the network model.

Figure 2 Flow diagram showing Boolean multi-criteria suitability analysis for transfer station locations

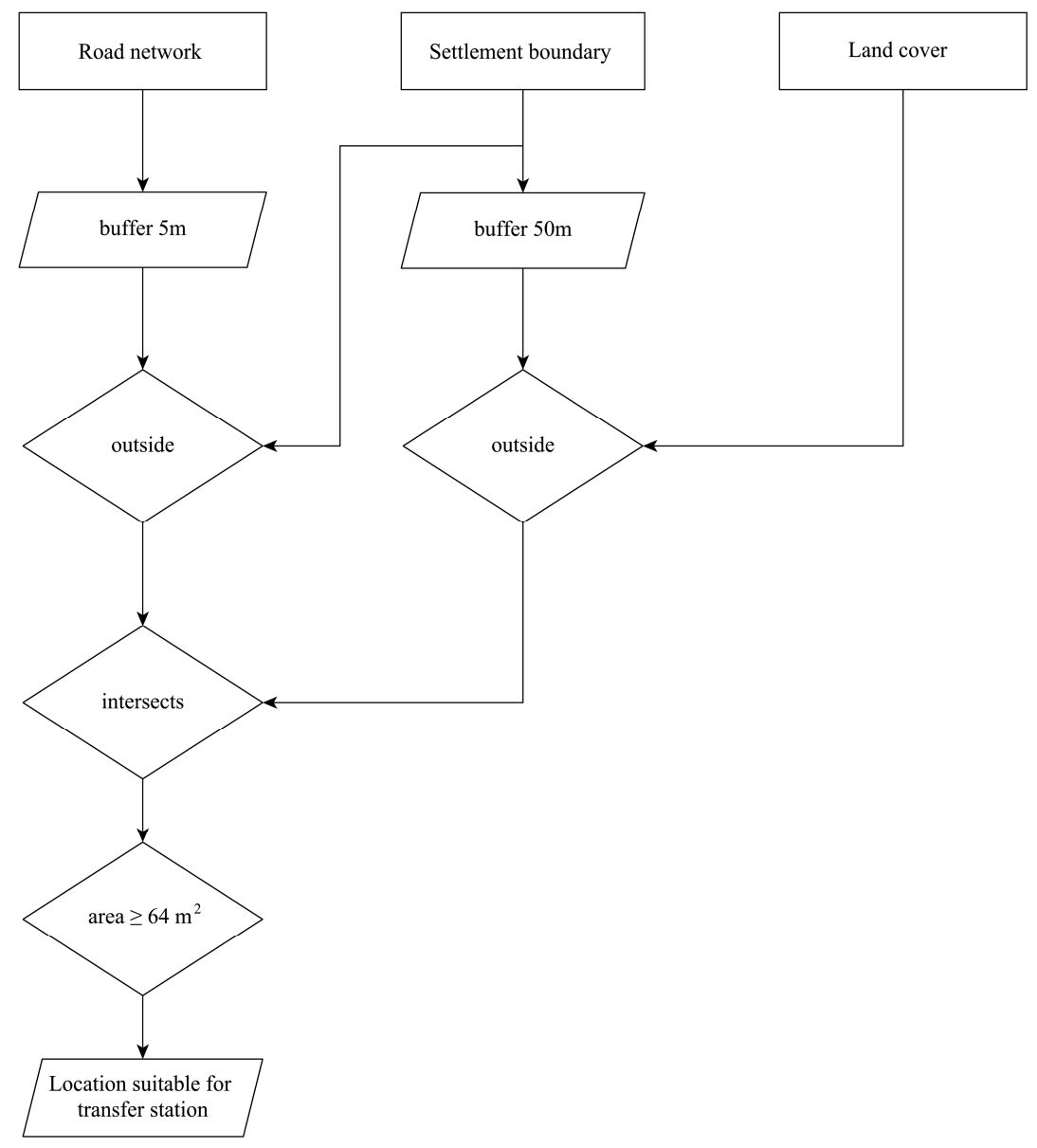




\subsection{Spatio-topological analysis of a road-based sanitation network}

Using the footpath network in Kibera and the surrounding road network for Nairobi a spatio-topological network model connecting Kibera's public toilets to the Dandora treatment works was constructed. The footpath network interchanged to the road network at transfer stations as identified by the suitability analysis. Network edges were weighted by travel time, based on each segment's geometric length and speed; for the footpath network speed was set to maximum Vacutug velocity $5 \mathrm{~km} / \mathrm{h}$, and external road speeds $25 \mathrm{~km} / \mathrm{h}$ based on empirical measurements from the literature (Davis et al., 2005).

The spatio-topological model of the proposed road-based sanitation network was created using the spatial database schema and coupled Python interface to the NetworkX graph analysis package, developed by Newcastle University (Barr et al., 2012). The completed network consisted of 19,558 edges covering 4,686,483 $\mathrm{Km}$ of road and 16,347 nodes representing road junctions, toilets, transfer stations and the treatment plant. The network model was used to optimise transfer station location based on minimising total sewage transportation time from each of Kibera's public toilets to the Dandora treatment plant.

Total sewage transport time $\left(t_{j}\right)$ was calculated in two stages [see equation (5)]. First, the time taken to transport one full load of waste from each public toilet in Kibera $(i)$ to a transfer station $(j)$ using a Vacutug travelling at $5 \mathrm{~km} / \mathrm{h}$, via the shortest possible path $\left(d_{i j}\right)$ was computed. Second, this was added to the time taken to transport accumulated waste from a transfer station $(j)$ to the Dandora treatment works $(k)$ using a large tanker travelling at $25 \mathrm{~km} / \mathrm{h}\left(d_{j k}\right)$. For both calculations, the shortest path between source and destination nodes was calculated using the Dijkstra algorithm. Iterating the calculation over each of the transfer stations in turn would reveal the transfer station that yielded the lowest total transport time [equation (5)].

$$
t_{j}=\min \left(\left(\sum_{i=1}^{n} d_{i j}\right)+d_{j k} i_{n} \frac{c_{l t}}{c_{v t}} \forall_{j}\right)
$$

Equation (5) shows that the transportation time of large tanker trips $\left(d_{j k}\right)$ is weighted by the number of toilets $\left(i_{n}\right)$ multiplied by the ratio between large tanker capacity $\left(c_{l t}\right)$ and Vacutug capacity $\left(c_{v t}\right)$. This accounts for the difference in sewage capacity between the two (large tanker: 10,000 litres, Vacutug: 500 litres). As a result only one large tanker trip is required from the transfer station for every 20 Vacutug trips between a toilet and transfer station, assuming that each transfer station capacity is equal to that of the large tanker. Thus, the total sewage transportation time via each transfer station is the time taken for a Vacutug journey from each of the 158 toilets in Kibera to the transfer station and the time for 7.9 large tanker trips required from the transfer station to the Dandora treatment plant.

\section{Results}

\subsection{Transfer station location suitability analysis}

The Boolean multi-criteria suitability analysis resulted in 14 areas being identified as suitable for transfer station locations. Figure 3 shows the distribution of these areas, with 
the majority of stations located in the northwest of Kibera. Only three stations deviate from this pattern: stations one and two are located to the east of the settlement, and station three to the south (see Figure 3).

The location of stations was determined primarily by the availability of land for development and suitable access to the Nairobi network for large tanker access. In relation to the Dandora treatment works, stations one and two have the shortest straight line distance $(\sim 25 \mathrm{~km})$ compared to the other locations and are also closest to the majority of public toilets which are situated in south-eastern Kibera (see Figure 3). Interestingly, stations four, five and six are located on a road that bisects two segments of northwest Kibera. As such the road is represented by an internal boundary line in the settlement boundary data (not shown in Figure 3), meaning that these stations have the lowest distance to the nearest toilet as compared to any of the other 11 transfer stations.

\subsection{Spatio-topological network optimisation of transfer station}

Table 1 shows the total sewage transportation time for each station, and highlights that station three has the lowest total sewage transportation time of any station at 42.39 hours. The location of station three to the south of Kibera provides the best balance between proximity to all 158 public toilets and access to the Nairobi road network for transportation of waste to the Dandora treatment works. The total sewage transportation time from station three is 5.51 hours less than that of station 14, the next fastest route (see Table 1). Station 14 is similarly situated to station three in that it is towards the horizontal centre of the settlement, as opposed to extreme east and west positions of the other 12 stations (see Figure 3). Furthermore, total sewage transport time from station three is 13.34 hours less than station four, the least efficient station, which is situated at the western end of the settlement. This result highlights that station four is both furthest away from both the treatment works and the majority of Kibera's toilets, increasing travel time for both Vacutug and large tanker journeys.

Table 1 Sewage transportation time for each transfer station

\begin{tabular}{lccc}
\hline $\begin{array}{l}\text { Transfer } \\
\text { station }\end{array}$ & $\begin{array}{c}\text { EVacutug time } \\
\text { (hours) }\end{array}$ & $\begin{array}{c}\text { Large tanker time } \\
\text { (hours) }\end{array}$ & $\begin{array}{c}\text { Total sewage transport time } \\
\text { (hours) }\end{array}$ \\
\hline 3 & 32.32 & 10.07 & 42.39 \\
14 & 37.99 & 9.91 & 47.90 \\
13 & 39.73 & 9.92 & 49.64 \\
11 & 40.21 & 9.97 & 50.18 \\
10 & 40.43 & 9.99 & 50.41 \\
9 & 40.56 & 10.00 & 50.56 \\
8 & 40.79 & 10.03 & 50.82 \\
7 & 41.55 & 10.13 & 51.69 \\
12 & 41.69 & 10.04 & 51.73 \\
1 & 43.09 & 8.96 & 52.05 \\
6 & 42.34 & 10.19 & 52.52 \\
2 & 43.97 & 9.08 & 53.05 \\
5 & 43.53 & 10.26 & 53.79 \\
4 & 45.37 & 10.36 & 55.73 \\
\hline
\end{tabular}


Figure 3 Map showing Kibera settlement, public toilets and identified transfer station locations (see online version for colours)

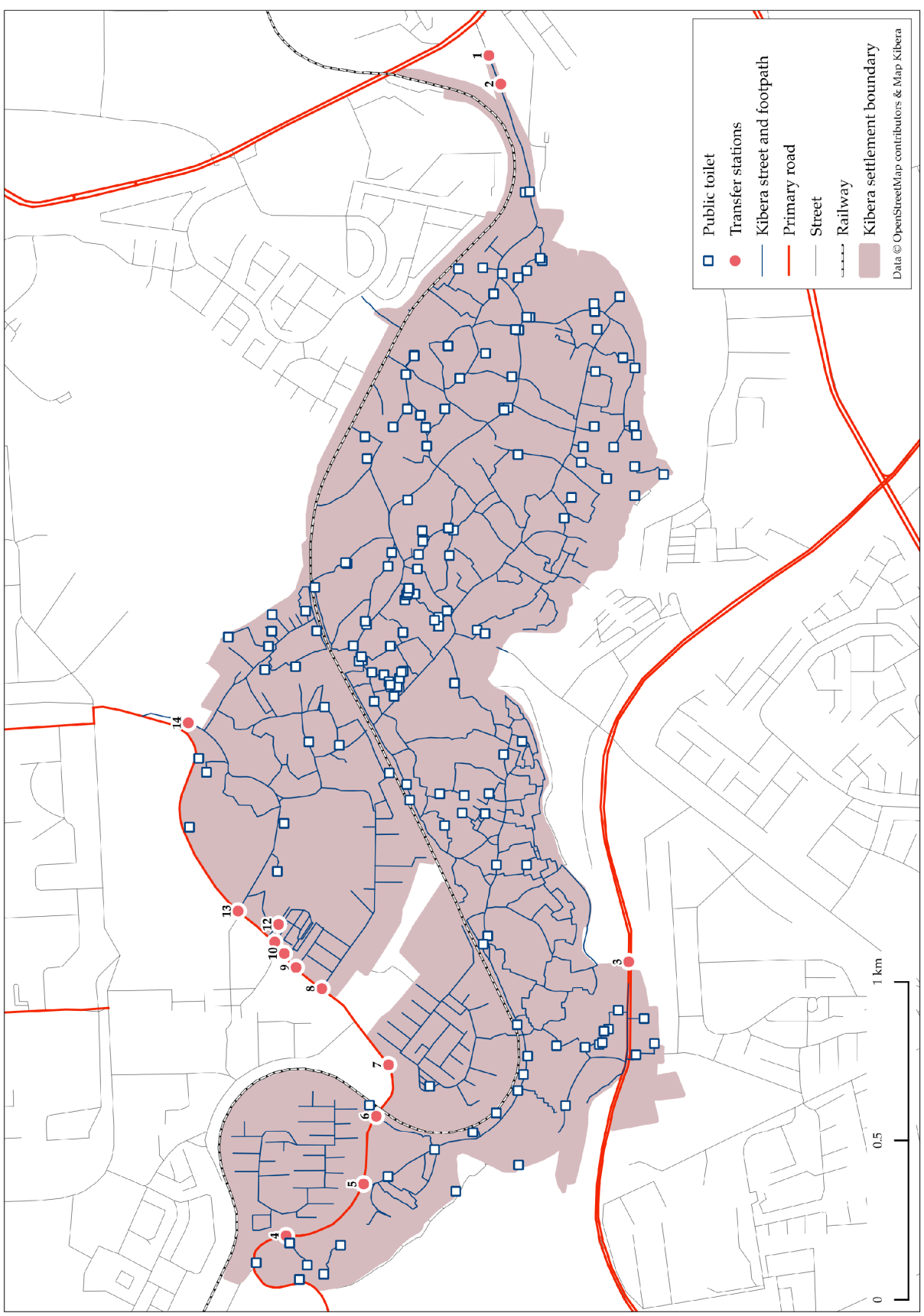


However, whilst station three exhibits the lowest overall sewage transport time the journey time from transfer station to treatment plant (large tanker journey time) is between 1.61 and 0.04 hours slower than the large tanker trip times for the next six fastest transfer stations (Table 1). These results suggest that Vacutug journey times have the greatest influence on overall sewage transportation time, and so optimum transfer station selection. This is supported by comparison of the standard deviation of Vacutug journey times from all stations in Table $1(\sigma=3.03, \bar{x}=40.97$ hours $)$, which are almost eight times that of large tanker journey times $(\sigma=0.39, \overline{\mathrm{x}}=9.92$ hours $)$. The smaller variance of large tanker journey times can be explained by the topology of Nairobi's road network, which due to a lack of ring roads often forces vehicles to traverse the city through the central business district (Gonzales et al., 2011) (see Figure 3). This results in a convergence of possible shortest path routes from each transfer station to the Dandora treatment works, minimising the differences in large tanker journey times.

\section{Conclusions}

Road-based sanitation solutions are increasingly being cited as a viable solution to the sanitation crises in informal settlements. Analysis of such systems has previously been unavailable due to limited data coverage in many informal settlements in developing nations worldwide. This study has demonstrated the utility of crowd-sourced geospatial data within a GIS to aid sanitation planning in informal settlements. In particular the ability to model a proposed road-based sanitation network affords the potential of evaluation and planning of infrastructure proposals prior to implementation. The analysis undertaken was achieved by combining two established techniques; first, a Boolean multi-criteria suitability analysis was used to identify 14 locations at the settlement periphery, which were deemed suitable for transfer station infrastructure. Second, using these locations a spatio-topological network model was constructed to model the transportation of waste from 158 public toilets within Kibera to the Dandora treatment works via each transfer station. Transfer station location was evaluated by total sewage transportation time and showed that intra-settlement travel time via Vacutug between toilet and transfer station was the critical factor in total transportation time.

However, while the results validated the effectiveness of geographical information systems combined analysis these approaches only provide a hypothetical model and require further on the ground information if they are to inform communities and decision makers. For example, the OpenStreetMap data does not capture information on land ownership or availability, or include private household toilets, both of which may alter suitability of identified transfer station locations. While such factors could be integrated into the suitability analysis there are also a number of other non-technocratic factors such as community willingness to implement such a system and infrastructure costs that need to be accounted for and should be investigated in future research.

The increasing size and number of informal settlements globally mean that engineers will increasingly need to develop and evaluate improved sanitation options to reduce health and environmental risks to these populations. Such solutions need to include road-based transportation as well as traditional piped sewerage, and operate in an economically sustainable manner. The research presented in this paper demonstrates as proof-of-concept how crowd-sourced geospatial data and open source GISs can be 
utilised for future feasibility studies as part of the sanitation planning process in developing nations.

\section{References}

Banerjee, S.G. and Morella, E. (2011) Africa's Water and Sanitation Infrastructure: Access, Affordability and Alternatives, The International Bank for Reconstruction and Development, Washington, DC, USA.

Barr, S., Holderness, T., Alderson, D., Robson, C. and Ford, A. (2012) 'An open source relational database schema and system for the analysis of large scale spatial interdependent infrastructure networks', Proceedings of the 4th Open Source GIS Conference, Nottingham, UK.

Berdou, E. (2011) Mediating Voices and Communicating Realities. Using Information Crowdsourcing Tools, Open Data Initiatives and Digital Media to Support and Protect the Vulnerable and Marginalised, Vulnerability and Poverty Reduction Research Team, Institute of Development Studies, Brighton, UK.

Binale, A. (2011) 'Umande trust bio-centre approach in slum upgrading', Les Cahiers d'Afriquede l'est, September, Vol. 44, pp.167-186.

Chowdhry, S. and Kone, D. (2012) Business Analysis of Fecal Sludge Management: Emptying and Transportation Services in Africa and Asia - Draft Final Report, Bill and Melinda Gates Foundation, Seatlle, WA, USA.

Davis, N., Lents, J., Osses, M., Nikkila, N. and Barth, M. (2005) 'Part 3: Developing countries: development and application of an international vehicle emissions model', Transportation Research Record, Vol. 1939, No. 1, pp.155-165.

Egenhofer, M.J. and Franzosa, R.D. (1991) 'Point-set topological spatial relations', International Journal of Geographical Information Systems, Vol. 5, No. 2, pp.161-174.

Engineering and Consulting Firms Association (2008) Project Formulation Study on Nairobi Metropolitan Development Planning Project, Engineering and Consulting Firms Association, Tokyo, Japan.

Gastner, M. and Newman, M. (2006) 'The spatial structure of networks', The European Physical Journal B - Condensed Matter and Complex Systems, Vol. 49, No. 2, pp.247-252.

Gonzales, E., Chavis, C., Li, Y. and Daganzo, C. (2011) 'Multimodal transport in Nairobi, Kenya: insights and recommendations with a macroscopic evidence based model', Proceedings of the Transportation Research Board 90th Annual Meeting, Washington, DC, USA.

Hagen, E. (2010) 'Putting Nairobi's slums on the map', Development Outreach, Vol. 12, No. 1, pp.41-43.

Haklay, M. and Weber, P. (2008) 'OpenStreetMap: user-generated street maps', Pervasive Computing, Vol. 7, No. 4, pp.12-18.

Holderness, T. (2014) 'Geosocial intelligence', IEEE Technology and Society Magazine, Vol. 33, No. 1 , pp.17-18.

Isunju, J.B., Schwartz, K., Schouten, M.A., Johnson, W.P. and van Dijk, M.P. (2011) 'Socio-economic aspects of improved sanitation in slums: a review', Public Health, Vol. 125, No. 6, pp.368-376.

Malczewski, J. (2006) 'GIS-based multicriteria decision analysis: a survey of the literature', International Journal of Geographical Information Science, Vol. 20, No. 7, pp.703-726.

Migurski, M. (2013) Metro Extracts [online] http://metro.teczno.com/ (accessed 30 April 2013).

O’Riordan, M. (2009) Investigation into Methods of Pit Latrine Emptying - Management of Sludge Accumulation in VIP Latrines, Water Research Commission (WRC), South Africa.

Paar, P. and Rekittke, J. (2011) 'Low-cost mapping and publishing methods for landscape architectural analysis and design in slum-upgrading projects', Future Internet, Vol. 3, No. 4, pp.228-247. 
Tilley, E., Lüthi, C., Morel, A., Zurbrügg, C. and Schertenleib, R. (2008) Compendium of Sanitation Systems and Technologies, Swiss Federal Institute of Aquatic Science and Technology, Eawag, Dübendorf, Switzerland.

United Nations (2005) The Millennium Development Goals Report 2005, United Nations Publications, New York, NY, USA.

Worboys, M. and Duckham, M. (2004) GIS: A Computing Perspective, CRC Press.

World Health Organisation (2012) Progress on Drinking Water and Sanitation: 2012 Update, WHO/UNICEF Joint Monitoring Programme for Water Supply and Sanitation, USA.

Zook, M., Graham, M., Shelton, T. and Gorman, S. (2010) 'Volunteered geographic information and crowdsourcing disaster relief: a case study of the Haitian earthquake', World Medical \& Health Policy, Vol. 2, No. 2, pp.7-33.

\section{Notation}

Equations (1) to (4)

A Nairobi road network

$B \quad$ Kibera settlement boundary

I Nairobi land cover

$A_{1} \quad$ elements in $A$ buffered to $5 \mathrm{~m}$

$B_{1}$ elements in $B$ buffered to $50 \mathrm{~m}$

$C$ elements in $A_{1}$ outside $B_{1}$

$D$ elements in $B_{1}$ outside $I$

$L \quad$ intersecting elements of $C$ and $D$

$T$ elements of $L$ with an area of $64 \mathrm{~m}^{2}$ or greater.

\section{Equation (5)}

$t_{j} \quad$ is the minimum sewage travel time for station $j$ where station $j$ has the lowest time of any station

$j \quad$ is the transfer station node

$i \quad$ is the public toilet node

$k \quad$ is the treatment plant node

$d_{i j}$ is the shortest path between toilet node $i$ and transfer station $j$ weighted by travel time

$d_{j k}$ is the shortest path between transfer station $j$ and treatment plant $k$ weighted by travel time

$i_{n} \quad$ is the number of public toilets

$c_{v t}$ is the Vacutug capacity

$c_{l t}$ is the large tanker capacity. 